\title{
Особенности развития крупнейших межрегиональных медиахолдингов России
}

\author{
Сергей Смирнов
}

В статье, дополняющей многоэтапное исследование концентрации СМИ в субъектах Российской Федерации, представлен анализ деятельности медиахолдингов, распространяющих свою деятельность сразу на несколько регионов страны. Выявлена специфика структур собственности ряда объединений СМИ, определены ключевые направления их деятельности и финансовое положение.

В ходе сравнительного анализа объектов выборки и с учетом ранее полученных результатов установлены две различные модели организации межрегионального медиахолдинга в России.

Ключевые слова: регион, медиахолдинг, юридическое лицо, учредитель, франшиза, модель.

DOI: 10.30547/mediaalmanah.5.2020.9399
@ Смирнов Сергей Сергеевич

кандидат филологических наук, доцент кафедры теории и экономики СМИ факультета журналистики МГУ имени М. В. Ломоносова

(г. Москва, Россия), smirnov_s@rambler.ru

\section{Введение}

Поэтапно изучив специфику развития медиахолдингов в 77 регионах России - Москве, Санкт-Петербурге и во всех субъектах федерации, столицы которых являются городами-миллионниками и городами-стотысячниками (Смирнов, Гасанов, Радаев, 2019 (а, б)), мы поставили перед собой задачу дополнить результаты исследовательского проекта еще одним актуальным элементом. Межрегиональный медиахолдинг (или медиагруппа) - явление для отечественного медиарынка относительно редкое. По крайней мере, число российских организаций, официально позиционирующих себя в качестве таковых, ограничено одним десятком. Важно сразу отметить, что понятие «межрегиональный медиахолдинг» не является синонимом понятия «федеральный медиахолдинг». И в том и в другом случае деятельность объединений СМИ представлена в разных субъектах федерации, но принципиальное отличие, с нашей точки зрения, заключается в «прописке» основной (исходной) организации - у межрегионального медиахолдинга она всегда находится не в столице страны и имеет медиаактивы в базовом для бизнеса регионе.

Формирование межрегиональных медиахолдингов связано с коренной трансформацией всей национальной медиасистемы 
в 1990-2000 гг., а именно с возникновением рыночных отношений и такого явления, как концентрация капитала (Вартанова, 2014; Засурский, 2001; Иваницкий, 2010; Пургин, 2014). На этот процесс, очевидно, оказывают влияние известные диспропорции в развитии медиасистем разных субъектов федерации (Кирия, Довбыш, 2014 (а, б)), а также весьма специфическая схема бюджетной экономической поддержки медиапредприятий на местах (Довбыш, Гудова, 2016) и традиционная непрозрачность бизнесов (Таиров, 2014). Свою роль играют технологические инновации, затрагивающие деятельность региональных медиа (Вырковский, Макеенко, 2014; Ершов, 2012), перестройка работы их редакций в условиях цифровой среды (Свитич, Смирнова, Шкондин, 2017). Мы можем констатировать, что этот общий контекст уже подробно рассмотрен и продолжает изучаться многими российскими исследователями. В то же время научных работ, посвященных именно развитию межрегиональных медиахолдингов, нами обнаружено не было. Возможно, это объясняется их малочисленностью, однако, на наш взгляд, межрегиональные медиахолдинги представляют собой отдельный, ни на что не похожий феномен российского медиарынка. И речь идет не только о структурной организации таких объединений СМИ: мы предполагаем, что в их деятельности явно преобладает коммерческий императив, а интересы органов власти разных уровней, напротив, выражены минимально.

\section{Методология}

Методология исследования объединений СМИ, как правило, именуемых медиахолдингами/медиагруппами, не претерпела изменений. Сначала нами отбиралось предприятие, контролирующее в группе регионов наибольшее количество местных медиаресурсов, информация о которых бралась из всех доступных открытых источников, включая реестры
Роскомнадзора1. Далее проводился анализ официальных сведений о структурах собственности и финансовой отчетности юридических лиц по базе ГМЦ Росстата2. Таким образом, выявлялись те параметры деятельности изучаемых организаций, которые являются абсолютно очевидными или объективно доказуемыми, а именно организационно-правовая форма головного юридического лица, наличие/отсутствие явной бюджетной финансовой поддержки предприятия, а также выбранная им стратегия деятельности на медиарынке (собственные медиабренды или федеральные франшизы).

Данный универсальный набор критериев ранее уже позволил нам выделить шесть основных моделей развития региональных медиахолдингов. Однако сейчас мы понимаем, что изначально выбранный принцип маркировки (наименования) этих моделей - по названиям субъектов Российской Федерации - является не вполне удачным, поскольку изменения, происходящие на региональных медиарынках, будут требовать их постоянной ремаркировки. В связи с этим мы решили скорректировать подход и впредь опираться только на типовые организационно-экономические характеристики медиахолдингов (см. табл. 1). Этот обновленный перечень моделей, безусловно, тоже не является константой и со временем может быть дополнен или сокращен. Но пока мы попытались найти возможные соответствия между ним и существующим опытом функционирования межрегиональных медиахолдингов.

\section{Результаты и анализ данных}

Мониторинг активности межрегионального медиабизнеса по открытым источникам выявил следующие результаты: относительно интегрированные объединения СМИ (использующие единый бренд) и ведущие свою деятельность сразу в нескольких субъектах Российской Федерации, действительно, встречаются нечасто. 
Таблица 1. Выявленные модели развития региональных медиахолдингов России

\begin{tabular}{|c|c|c|}
\hline $\begin{array}{l}\text { Первичное } \\
\text { наименование } \\
\text { модели* }\end{array}$ & Краткая характеристика модели* & $\begin{array}{c}\text { Уточненное } \\
\text { наименование } \\
\text { модели }\end{array}$ \\
\hline $\begin{array}{l}\text { Красноярско- } \\
\text { Пермская }\end{array}$ & $\begin{array}{l}\text { Медиахолдинг является коммерческой } \\
\text { организацией; не получает явных } \\
\text { государственных дотаций; работает не только } \\
\text { с региональными, но и с федеральными } \\
\text { брендами СМИ. }\end{array}$ & $\begin{array}{l}\text { Коммерческо- } \\
\text { небюджетная, } \\
\text { открытая }\end{array}$ \\
\hline $\begin{array}{l}\text { Башкортостанско- } \\
\text { Новосибирская }\end{array}$ & $\begin{array}{l}\text { Медиахолдинг является некоммерческой } \\
\text { организацией; получает явные государственные } \\
\text { дотации; работает только с региональными } \\
\text { брендами СМИ. }\end{array}$ & $\begin{array}{l}\text { Государственно- } \\
\text { бюджетная, } \\
\text { закрытая }\end{array}$ \\
\hline $\begin{array}{l}\text { Белгородско- } \\
\text { Челябинская }\end{array}$ & $\begin{array}{l}\text { Медиахолдинг является некоммерческой } \\
\text { организацией; получает явные государственные } \\
\text { дотации; работает не только с региональными, } \\
\text { но и с федеральными брендами СМИ. }\end{array}$ & $\begin{array}{l}\text { Государственно- } \\
\text { бюджетная, } \\
\text { открытая }\end{array}$ \\
\hline $\begin{array}{l}\text { Владимирско- } \\
\text { Тюменская }\end{array}$ & $\begin{array}{l}\text { Медиахолдинг является формально } \\
\text { коммерческой организацией; получает явные } \\
\text { государственные дотации; работает не только } \\
\text { с региональными, но и с федеральными } \\
\text { брендами СМи. }\end{array}$ & $\begin{array}{l}\text { Коммерческо- } \\
\text { бюджетная, } \\
\text { открытая }\end{array}$ \\
\hline $\begin{array}{l}\text { Вологодско- } \\
\text { Нижегородская }\end{array}$ & $\begin{array}{l}\text { Медиахолдинг является коммерческой } \\
\text { организацией; не получает явных } \\
\text { государственных дотаций; работает только } \\
\text { с региональными брендами СМИ. }\end{array}$ & $\begin{array}{l}\text { Коммерческо- } \\
\text { небюджетная, } \\
\text { закрытая }\end{array}$ \\
\hline $\begin{array}{l}\text { Московско- } \\
\text { Татарстанская }\end{array}$ & $\begin{array}{l}\text { Медиахолдинг является формально } \\
\text { коммерческой организацией; получает явные } \\
\text { государственные дотации; работает только } \\
\text { с региональными брендами СМИ. }\end{array}$ & $\begin{array}{l}\text { Коммерческо- } \\
\text { бюджетная, } \\
\text { закрытая }\end{array}$ \\
\hline
\end{tabular}

*Источник: Смирнов, Гасанов, Радаев, 2019 (б): 61.

В общей сложности нам удалось обнаружить только семь таких медиахолдингов ${ }^{3}$. Ниже мы дадим краткую характеристику каждому из них, а также представим сводные организационно-экономические характеристики (см. табл. 2).

«Абак-Пресс». Издательский дом «АбакПресс», основанный в 1992 г. в Свердловской области, сегодня представлен на медиарынках более чем 30 регионов России. Основной вид деятельности - оригинальные печатные и сетевые издания (ключевые проекты: «Пульс цен», «Я покупаю», Blizko.ru, Dk.ru). Головная организация ИД «Абак-Пресс» расположена в Екатеринбурге.

«Алтапресс». Издательский дом «Алтапресс», созданный в 1990 г. в Алтайском крае, в настоящее время охватывает и медиа- рынок соседней Республики Алтай. Основной вид деятельности - оригинальные печатные и сетевые издания (ключевые проекты: «Свободный курс», «Купи-Продай», «Маркер-Экспресс», «Телепарк», Altapress. ru и др.). Головная организация ИД «Алтапресс» находится в Барнауле.

«Выбери Радио». Группа компаний «Выбери Радио»4, окончательно сформированная под этим брендом в 2008 г., в настоящее время ведет деятельность в 15 регионах Российской Федерации. Объединение включает 95 радиостанций, большинство из которых выступают региональными партнерами федеральных вещателей («Европа Плюс», «Авторадио», «Русское радио», «Радио Шансон», «Радио Дача», «Наше Радио» и др.), а в ряде случаев являются чисто 
региональными проектами («Радиола», «Городская волна», «54 Радио»). Головная организация у ГК «Выбери радио» формально расположена в Москве, но выполняет исключительно управленческие функции (не осуществляет вещания).

«Медиа Инвест». Холдинг «Медиа Инвест», основанный в Свердловской области в 2015 г. (изначально как «Ура Медиа»), представляет собой объединение региональных общественно-политических интернет-порталов (Rostovgazeta.ru, Inkazan.ru, Karelinform.ru, «Новости Волгограда», «Город 55», «Восток Медиа» и др.). На данный момент деятельность ведется как минимум в 14 субъектах РФ. Головная организация холдинга находится в Москве, но сама не выступает издателем порталов. При этом в 2016 г. «Медиа Инвест» приобрел газету «Советский спорт», что свидетельствует о намерениях трансформироваться в игрока федерального уровня.

«Радио Си» (Радиогруппа Н. Грахова). Создав также в Свердловской области первую радиостанцию в 1992 г., группа Н. Грахова в настоящее время ведет деятельность на медиарынках семи регионов России. Часть радиостанций объединения выступают партнерами федеральных вещателей («Дорожное радио», "Эхо Москвы», Love Radio, «Серебряный дождь» и др.), часть являются исключительно региональными проектами («Радио Си», «Радио Пилот», «Джем FM», «Рок-Арсенал», «Радио СК» и др.). Головная организация группы Н. Грахова расположена в Екатеринбурге.

«Федерал Пресс». История холдинга «Федерал Пресс» началась в 2007 г. в той же Свердловской области с запуска ключевого проекта - сетевого информационного агентства Fedpress.ru, имеющего на данный момент представительства во всех федеральных округах России. Также в «Федерал Пресс» входит онлайн-издание Globalcity. info. Головная организация холдинга находится в Екатеринбурге. В 2020 г. владелец «Федерал Пресс» И. Еремин приобрел газету «Ведомости», но активы не были объединены.

PrimaMedia. Холдинг PrimaMedia стартовал в Приморском крае с одноименного информационного агентства в 2005 г. На сегодняшний день деятельность ведется в 11 регионах России, где запущены собственные аналогичные проекты (AmurMedia.ru, SakhalinMedia.ru, IrkutskMedia.ru, MagadanMedia.ru, YakutiaMedia.ru, KrasnodarMedia. su и др.). Головная организация холдинга PrimaMedia расположена во Владивостоке.

Первое, что обращает на себя внимание при анализе организационно-экономических характеристик межрегиональных медиахолдингов России, это простота имущественных схем: единственной используемой ОПФ является общество с ограниченной ответственностью, а собственниками головных организаций в большинстве случаев выступают физические лица. И совершенно однозначно здесь можно констатировать полное доминирование частного капитала (государственного нет вообще). Это вполне можно объяснить тем, что все политические и экономические интересы региональных властей сконцентрированы на медиарынках конкретных субъектов федерации, а относительно размытое межрегиональное поле деятельности по умолчанию остается как бы ничьим, и поэтому его заполняют коммерческие структуры. Конечно, и в этом случае не исключены какие-то формальные или неформальные связи частных СМИ и органов власти, но тем не менее прямого государственного участия в межрегиональных медиахолдингах не наблюдается.

Отметим также, что рассматриваемые объединения СМИ задействуют как горизонтальный, так и диагональный тип роста, при этом заимствованные бренды используются межрегиональными медиахолдингами только на радиорынке, который и является наиболее пригодным для франшиз. Интересен географический аспект: в четырех случаях базовым регионом для 


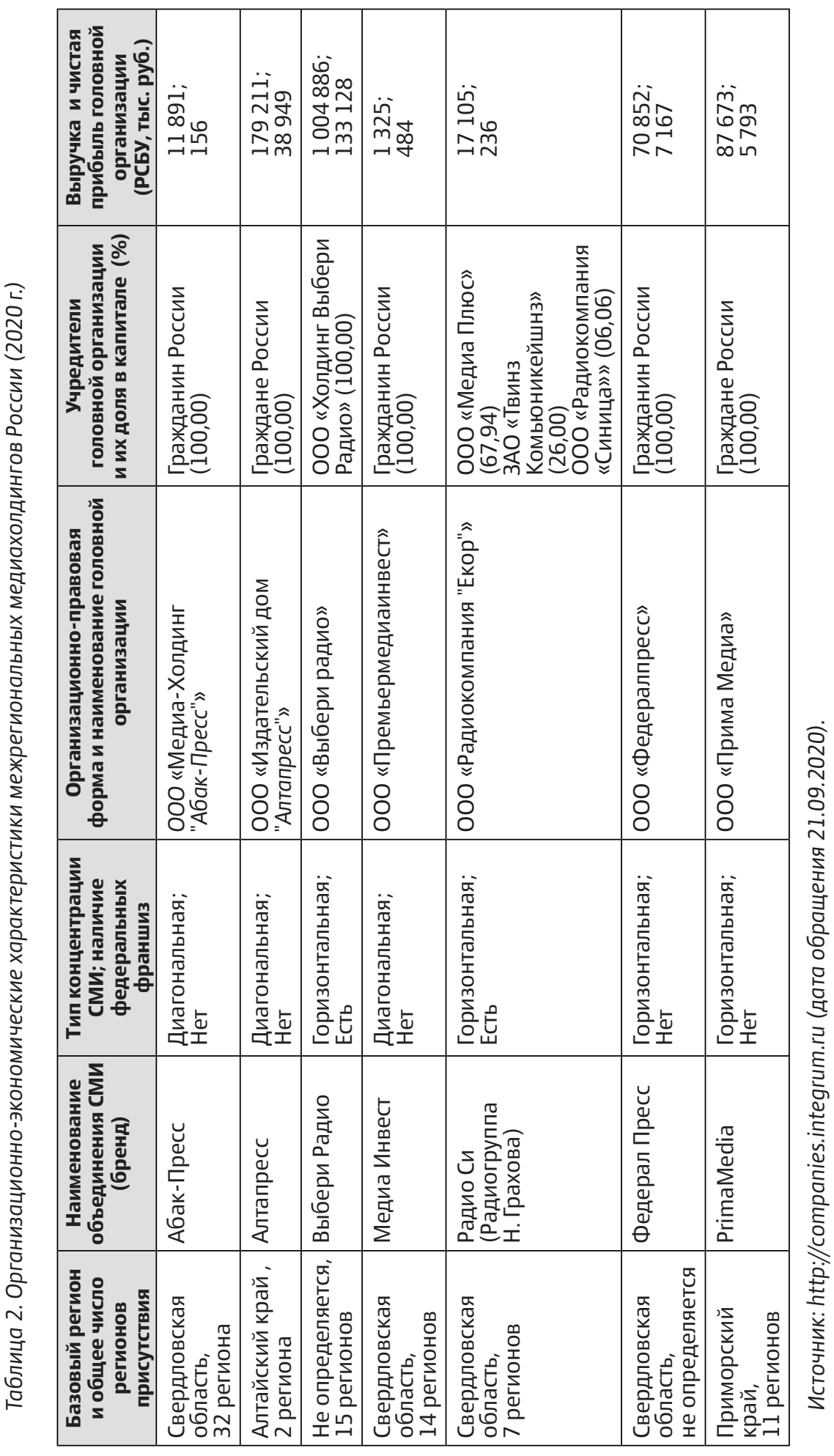


Таблица 3. Выявленные модели развития межрегиональных медиахолдингов России

\begin{tabular}{|l|l|c|}
\hline \multicolumn{1}{|c|}{\begin{tabular}{c}
\multicolumn{1}{|c|}{ Наименование } \\
модели
\end{tabular}} & \multicolumn{1}{|c|}{ Краткая характеристика модели* } & \multicolumn{1}{|c|}{$\begin{array}{c}\text { Количество кейсов } \\
\text { (N=7) }\end{array}$} \\
\hline $\begin{array}{l}\text { Коммерческо- } \\
\text { небюджетная, } \\
\text { закрытая }\end{array}$ & $\begin{array}{l}\text { Медиахолдинг является коммерческой } \\
\text { организацией; не получает явных } \\
\text { государственных дотаций; работает только } \\
\text { с региональными брендами СМИ. }\end{array}$ & 5 \\
\hline $\begin{array}{l}\text { Коммерческо- } \\
\text { небюджетная, } \\
\text { открытая }\end{array}$ & $\begin{array}{l}\text { Медиахолдинг является коммерческой } \\
\text { организацией; не получает явных } \\
\text { государственных дотаций; работает не только } \\
\text { срегиональными, но и с федеральными } \\
\text { брендами СМИ. }\end{array}$ & 2 \\
\hline
\end{tabular}

Источник: составлено автором

медиахолдинга является Свердловская область, в этом, вероятно, важную роль сыграл потенциал экономического центра Урала. Не оказались неожиданными данные финансовой отчетности головных организаций - официальные показатели, к сожалению, иногда выглядят совершенно условными, что не дает возможности составить представление о реальном экономическом положении всего объединения. Но признаки системной бюджетной финансовой поддержки не были найдены ни в одном случае. Таким образом, в результате нам удалось выявить две очевидные модели развития межрегионального медиахолдинга в России (см. табл. 3). Оба варианта не стали новыми, а совпали с обнаруженными нами ранее на уровне региональных объединений СМИ.

\section{Выводы}

Подводя итоги исследования, прежде всего, отметим, что межрегиональное начало в развитии российских медиахолдингов пока все же выражено относительно слабо. Но у этого вектора есть своя перспектива, поскольку в стране имеются крупные макрорегионы (Кавказ, Поволжье, Сибирь и т.п.), обладающие внутренней социально-экономической идентичностью, что и требуется для формирования соответствующих объединений СМИ. Вопрос в том, что может стать главным драйвером этого процесса в обозримом будущем.

Исключительно важно и то, что уже существующие межрегиональные медиахолдинги являются результатом проявления именно частной предпринимательской инициативы. Две выявленные в рамках исследования модели различаются только по одному параметру - использованию федеральных медиабрендов, но деятельность всех рассмотренных игроков явно нацелена на коммерческую целесообразность. Понятно и то, что дальнейшее развитие межрегиональных медиахолдингов в России будет зависеть от целого комплекса факторов, связанных с общей экономической и политической обстановкой на медиарынках разных субъектов РФ. В связи с этим мы не считаем тему окончательно закрытой, и планируем возвращаться к данному исследованию, обновляя массив данных и уточняя концептуальные результаты.

\section{Примечания}

1 Роскомнадзор. Массовые коммуникации. Реестры. Режим доступа: https://rkn.gov. $\mathrm{ru} /$ mass-communications/reestr 
2 Финансовые показатели предприятий за 2018 г., сданные в рамках апрельской финансовой отчетности 2019 г., являются последними полностью доступными данными на момент написания статьи.

з В ряде случаев межрегиональными медиахолдингами именуются организации иного рода, а именно рекламные селлеры, ведущие деятельность в нескольких субъектах РФ (например, «Народная Медиа Группа» и «Региональная Медиа Группа»).

4 В 2019 г. ГК «Выбери Радио» вошла в холдинг «Медиа-1» И. Таврина.

\section{Библиография}

Вартанова Е.Л. Постсоветские трансформации российских СМИ и журналистики. М.: МедиаМир, 2014.

Вырковский А.В., Макеенко М.И. Региональное телевидение России на пороге цифровой эпохи. М.: МедиаМир, 2014.

Довбыш О.С., Гудова Е.А. Государственные информационные контракты и их значение для медиарынков российских регионов // Мониторинг общественного мнения: Экономические и социальные перемены. 2016. № 6. С. 156-174.

Ершов Ю.М. Телевидение регионов в поиске моделей развития. М.: Изд-во Моск. ун-та, 2012.

Засурский И.И. Реконструкция России. Масс-медиа и политика в 90-е годы. М.: Издво Моск. ун-та, 2001.

Иваницкий В.Л. Модернизация журналистики: методологический этюд. М.: Изд-во Моск. ун-та, 2010.

Кирия И.В., Довбыш О.С. (а) Региональные диспропорции в развитии медиасистем в России // Вестн. Моск. ун-та. Сер. 10: Журналистика. 2014. № 3. С. 4-14.

Кирия И.В., Довбыш О.С. (б) Региональные диспропорции в развитии медиасистем в России // Вестн. Моск. ун-та. Сер. 10: Журналистика. 2014. № 4. С. 84-104.

Пургин Ю.П. Региональные медиахолдинги в системе отечественной медиаиндустрии // Журналист. Социальные коммуникации. 2014. № 4. С. 5-19.

Свитич Л.Г., Смирнова О.В., Шкондин М.В. Газеты и журналы в медиасистеме городов-миллионников: социологическое исследование // Вестн. Моск. ун-та. Сер. 10: Журналистика. 2017. № 5. С. 3-29.

Смирнов С.С., Гасанов Э.С., Радаев И.В. (а) Особенности развития крупнейших региональных медиахолдингов России (города-стотысячники: ЦФО, СЗФО, ПФО) // МедиаАльманах. 2019. № 2. С. 80-88. DOI: 10.30547/mediaalmanah.2.2019.8088

Смирнов С.С., Гасанов Э.С., Радаев И.В. (б) Особенности развития крупнейших региональных медиахолдингов России (города-стотысячники: ЮФО, СКФО, УФО, СФО, ДФО) // МедиаАльманах. 2019. № 3. С. 54-63.DOI: 10.30547/mediaalmanah.3.2019.5463

Таиров А.Р. Проблемы обеспечения прозрачности региональных рынков СМИ // Медиа. Информация. Коммуникация. 2014. № 9. С. 4-6. 